\title{
Fungal endophytes affect plant response to leaf litter with contrasting chemical traits
}

\author{
M. Idbella1,2,3, M. Zotti², G. Cesarano², T. Fechtali1 ${ }^{1}$, S. Mazzoleni² and G. Bonanomi² \\ ${ }^{1}$ Laboratory of Biosciences, Faculty of Sciences and Techniques, Hassan II University, Casablanca, Morocco \\ ${ }^{2}$ Department of Agricultural Sciences, University of Naples Federico II, via Università 100, 80055 Portici (NA), Italy \\ ${ }^{3}$ Corresponding author. Email: mohamed.idbella@unina.it
}

Keywords: Endophytic fungi; Inhibition effect; Litter decomposition; Seedling growth; Soil microbial communities.

\begin{abstract}
Plant litter decomposition is a crucial process of nutrient cycling within ecosystems. However, many studies have shown that, apart from its several beneficial effects, organic matter decomposition can be disadvantageous to seed germination, seedling growth, and physiological activity of plants. Litter decomposition was reported to affect both plants and their associated soil microbial communities. The aim of this work was to test the relationships between seed-associated endophytic fungi on the either positive or negative plant's response to different litter types. Leaf material of four species was collected and used in a decomposition experiment inside a growth chamber for 120 days. The plant growth experiment was set in a greenhouse using Trifolium repens and Triticum durum with and without their associated endophytic fungi in the presence of the different litter species at two decay levels (fresh litter and after 120 days of decomposition). Results demonstrated that fresh litter exerted a strong inhibition effect on the plant total biomass when compared to decomposed litter. Moreover, seed-associated endophytic fungi enhanced the inhibitory effect of litter in the observed experimental conditions. The removal of seed-associated endophytic fungi improved the capacity of tested plants to resist to litter inhibitory effect.
\end{abstract}

Abbreviation: EF - Endophytic Fungi.

\section{Introduction}

Litter decomposition is a fundamental ecological process for sustaining life on earth, as it is maintaining ecosystems functions and nutrient cycling (Berg and Laskowski 2005). Broadly defined, decomposition consists of the breakingdown of organic matter into $\mathrm{CO}_{2}$ and nutrients via physical, biological and chemical means (Aerts 1997, Krishna and Mohan 2017). During these processes, a large fraction of carbon is released into the atmosphere while a smaller fraction is transformed into humus substances, which accumulate in the soil for a long time and are reused by microbes and plants (Berg and McClaugherty 2014).

The rate of the organic-matter decay is affected by litter quality (Meentemeyer 1978, Manzoni et al. 2010, Bonanomi et al. 2013), and climatic factors (Aerts 1997). Litter decomposition is responsible for generating a vital part of the nutrient budget on the scale of ecosystems and the whole biosphere (Vesterdal 1999, Krishna and Mohan 2017). However, many studies have demonstrated a detrimental effect of decomposing litter on seed germination, seedling survival, and plant growth (Van der Putten et al. 1997, Bonanomi et al. 2005, Zhang et al. 2015). Allelochemicals, mostly referable to 'secondary metabolites', have been reported to affect neighboring plant individuals and soil microbial communities including bacteria, nematodes, pathogens and mycorrhizal fungi (Schenk et al. 1999, Souto et al. 2000, Shaukat et al. 2002). Litter decomposition produces various organic compounds that are subjected to several physical, chemical, and biologi- cal processes in the soil, such as sorption and polymerization by soil organic matter and clay minerals (Makino et al. 1996), and chemical transformation by microorganisms (Blum et al. 1999). These changes affect both the composition and quantity of allelochemicals, which may either increase or decrease the phytotoxicity of decomposing plant litter (An et al. 2001). Investigations about phytotoxicity dynamics have demonstrated that, generally, most severe inhibition effects have been observed in early stages of decomposition, followed by decreases in phytotoxicity (Cochrane 1948, Jäderlund et al. 1996, Bonanomi et al. 2006). Recently, Mazzoleni et al (2015) showed that while the early litter phytotoxicity, mostly acting on heterospecific plants, is typically related to labile compounds, the long-term self-toxicity may build-up during decomposition due to accumulating of self-DNA of the same plant species in the decaying organic materials.

Since the 1980s, an increasing number of studies have demonstrated that soil microorganisms are the main decomposers by consuming over $\sim 95 \%$ of plant detritus, leaving the slight proportion of $\sim 5 \%$ to soil animals (Berg and Laskowski 2005, McGroddy et al. 2004, Cleveland and Liptzin 2007). Among the soil microbial population, fungi are the leading decomposers and have more than $75 \%$ greater potential to crumble organic matter than other microorganisms (Kjoller and Struwe 1992, Krishna and Mohan 2017). One notable subgroup in the fungal kingdom is the endophytic fungi.

Fungal endophytes have been well-studied over the past few decades (Hyde and Soytong 2008). Endophytic fungi are defined as plant associated fungi that colonize and live, dur- 
ing a specific phase of their life cycle, within a part of a plant without causing any apparent damage or disease to their host (Hardoim et al. 2015, Puri et al. 2016). Endophytic fungi have been reported as natural residents within several host plants (Saikkonen et al. 1998, Suryanarayanan 2013, Bamisile et al. 2018). Different species of endophytes can be enclosed in a single part of the plant (leaf, stem, seed or root) (Cherry et al. 1999, Vega et al. 2008, Bamisile et al. 2018). In general, fungal endophytes are known to be beneficial, protecting their host plants from pathogens (Campanile et al. 2007), by producing secondary metabolites (Schulz et al. 1999), and cell wall-degrading enzymes (Cao et al. 2009), or by inducing systemic resistance (Vu et al. 2006). Moreover, they are capable of protecting their host against several abiotic stresses as well, such as drought (Elmi and West 1995), salinity, nutrient depletion (Malinowski et al. 2000), flooding (Giordano et al. 2009), and thermal stress (Redman et al. 2002). On the other hand, few species have been reported as pathogens, causing disease to the host, after a period of latency (Mayerhofer et al. 2012, Kia et al. 2017, Sikora et al. 2007). Other species are considered neutral without implying benefits nor damages (Sikora et al. 2008). In addition to their role within plants, many endophytes can survive and grow as saprophytes in soils (Peay et al. 2016), and include species that are decomposers of plant material (Song et al. 2017). However, the exact conditions under which most endophyte species function remain largely unknown (Newsham 2011).

Research on the interaction between allelopathy and endophytic fungi has been sufficiently explored. Yue et al (1998) revealed, for instance, the detoxification of the allelochemicals Benzoxazolin-2-one (BOA) and 6-methoxybenzoxazolin2-one (MBOA) produced by corn to N-(2-hydroxyphenyl) and $\mathrm{N}$-(2-hydroxy-4-methoxyphenyl) malonamic acids, respectively by the endophytic fungus of corn Fusarium moniliforme J. Sheld. Afterwards, Zikmundová et al (2002) studied the biotransformation and detoxification of two allelochemicals BOA and HBOA by four endophytic fungi isolated from Aphelandra tetragona (Vahl.) Nees. However, the effect of these endophytic fungi on the response of plants to litter decomposition and associated phytotoxic compounds has never been tested. Moreover, litter having different chemical traits, depending on plant type and decomposition age, could have variable effects on plants and seed endophytic fungi. Therefore, the aim of this work is, firstly, to test the effect of different litter type on the response of two target species, Trifolium repens L. and Triticum durum L. Secondly, we assessed the impact of seed-associated endophytic fungi on the target species response to four litter species having variable chemical traits. The tested hypothesis was that fungal endophytes would enhance the resistance of plants to litter inhibitory effect, based on their known beneficial effects reported on the host plants.

\section{Material and methods}

\subsection{Plant litter collection}

Litter of four species of different functional groups were selected including a forb (Hedera helix L.), a deciduous tree
(Fraxinus ornus L.), an evergreen tree (Quercus ilex L.), and a deciduous, nitrogen fixing tree (Alnus glutinosa L.). The species, belonging to different functional groups, were selected to evaluate the effect of a range of chemical traits on the target plant response with and without associated endophytic fungi. Litter samples were taken from vegetation types of both Mediterranean (H. helix and $Q$. ilex) and temperate environments (A. glutinosa and F. ornus) (Campania region, Southern Italy). For each species, the litter was collected by placing nets under the canopy. The fallen leaves were periodically collected, transferred to laboratory, dried in a ventilated chamber $\left(40^{\circ} \mathrm{C}\right.$ for 10 days), chopped with scissors (size $<3$ $\mathrm{cm}$ ), and stored at room temperature (Bonanomi et al. 2011).

\subsection{Decomposition experiment}

In open fields, litter decomposition essentially relies upon organic matter quality, water availability and temperature (Berg and McClaugherty 2014). In order to focus only on litter quality effects, the decomposition experiment was carried out under controlled conditions. The litter decomposition experiment was performed in a growth chamber with optimal conditions of water availability and temperature, since the litter was watered every 7 days with sterile distilled water at holding capacity, and the temperature was $18 \pm 2{ }^{\circ} \mathrm{C}$ at night and $24 \pm 2{ }^{\circ} \mathrm{C}$ during the day. Dry leaf litter $(100 \mathrm{~g}$ for each species in 3 replicates) was placed inside plastic trays (size $30 \mathrm{~cm} \times 50 \mathrm{~cm} \times 50 \mathrm{~cm}$ ). A microbial inoculum, obtained by mixing $10 \mathrm{~g}$ of soil from the fields of litter collection (top 10 $\mathrm{cm}$ ) and $90 \mathrm{~g}$ of water was added improve the outset and the maintenance of the decomposition process (Bonanomi et al. 2011). The microbial inoculum was sprinkled over the litter trays. Decomposed litter was collected 120 days of incubation. A total of 8 samples were obtained (4 litter species $\times 2$ sampling dates, 0 and 120 days of incubation). Litter was air dried in paper bags in a ventilated chamber at $40^{\circ} \mathrm{C}$ until a constant weight was reached.

\subsection{Litter chemical analyses}

All litter samples were characterized for total $\mathrm{C}$ and $\mathrm{N}$ content by flash combustion of microsamples $(5 \mathrm{mg}$ of litter) using an elemental analyzer (Flash EA2000 Thermo). The relative content of acid-detergent hydrolysable fraction (thereafter indicated as labile $\mathrm{C}$ ) was determined by mild acid hydrolysis with $0.5 \mathrm{M} \mathrm{H}_{2} \mathrm{SO}_{4}$ and the detergent cetyltrimethylammonium $\left(20 \mathrm{~g} \mathrm{l}^{-1}\right)$. Proximate cellulose was quantified as hydrolysable fraction after an extreme sulfuric acid treatment (loss due to $72 \% \mathrm{H}_{2} \mathrm{SO}_{4}$ for 3 hours), and proximate lignin as the unhydrolyzable fraction (loss upon ignition after the above sulfuric treatment (Gessner 2005). All carbon fractions are presented as ash-free dry mass.

\subsection{Effects of the fungal endophytes on plant response to litter}

To test the effect of seed-associated endophytic fungi of two target plants (T. repens and T. durum) in response to litter 
of different species and ages, we conducted a greenhouse experiment in the period between March and June 2018. Target species used in this experiment were chosen due to their short life-span, being agricultural annual, and because belong to different functional types, i.e., a grass and a nitrogen fixing species. Moreover, test plants are well known to suffering from soil sickness caused by litter phytotoxicity (Cesarano et al. 2017). Therefore, the aim was to test the effect of seed associated fungi in modulating the soil sickness problem for agricultural plants.

T. repens and T. durum plants were grown in 54 pots with 2 plants in each. A total of 27 pots were planted with seedlings containing endophytic fungi (hereafter indicated as $\mathrm{EF}^{+}$) and other 27 without their natural fungal endophytes (hereafter indicated as EF-), in the presence of litter of four species (H. helix, A. glutinosa, F. ornus and Q. ilex) at two ages (fresh $0 \mathrm{~d}$ and decomposed for $120 \mathrm{~d}$ ). The control was without litter addiction while in the litter treatments the organic matter was incorporated at rate of $1 \%$ by weight. Overall, we obtained 18 experimental treatments ( 8 litter types plus untreated control, with $\mathrm{EF}^{+}$and without $\mathrm{EF}$ - endophytic fungi) for a total of 108 pots (Fig. 1).

To obtain EF-, the seeds (purchased from commercial secured sources without any previous treatments) were treated with the fungicide Propiconazole (TILT ( 25 EC; $0.25 \mathrm{ml}$ per $100 \mathrm{~g}$ of seeds, with a dilution of $1 \mathrm{ml} / \mathrm{L}$ ) to eliminate the endophyte. Seeds were dipped for $30 \mathrm{~min}$ in the fungicide solution and, thereafter, washed three time in distilled water to eliminate treatment residues. Subsequently, seeds were dried in microbiological hood with air laminar flux for $20 \mathrm{~min}$. Fungicide-treated and untreated seeds were cultivated in adjacent $1 \mathrm{~m}^{2}$ trays in the laboratory for a pre-growth phase to avoid the litter shock due to seed direct contact with litter, and the seedlings were gently pulled to preserve the roots and put back into the experiment corresponding pots as EF- and EF+ seedlings, respectively. The isolation test on $2 \%$ malt extract (Difco) agar medium, as reported by Hata et al (1998), confirmed the absence of endophytic fungi in the treated seeds. The isolation test was assessed as follow: after removing the basal sheath, seeds were dipped in $70 \%$ ethanol for $1 \mathrm{~min}$ to wet the surface, surface sterilized for $15 \mathrm{~min}$ in a solution of $15 \%$ hydrogen peroxide, dipped again for $1 \mathrm{~min}$ in $70 \%$ ethanol, then rinsed in sterilized distilled water. From the surface-sterilized seeds, several segments approximately $5 \mathrm{~mm}$ long were aseptically cut off with a sterile scalpel. The segments were then placed on $2 \%$ malt extract agar medium in a $9 \mathrm{~cm}$ diameter plate and incubated at $20^{\circ} \mathrm{C}$ for 21 days and then checked for presence of fungal colonies.

The experimental pots were filled with soil (23.48\% sand,

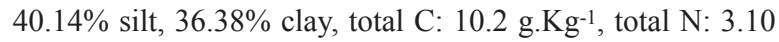
g. $\mathrm{Kg}^{-1}$ with an electrical conductivity of $0.29 \mathrm{dS} . \mathrm{m}^{-1}$ ) previously collected (upper $10 \mathrm{~cm}$ ) from a farm located in the Campania Region, southern Italy (E:14 $18^{\prime}, \mathrm{N}: 40^{\circ} 51^{\prime} ; 4 \mathrm{~m}$ a.s.1.). The soil was sterilized before the start of the experiment by autoclaving at $1 \mathrm{~atm}$ pressure, $120^{\circ} \mathrm{C}$, for $1 \mathrm{~h}$, three times with $24 \mathrm{~h}$ interval. Pots were kept in a greenhouse and were periodically watered to field capacity. To avoid contamination among different pots through leaching or splashing when watering, each pot was located inside an individual plastic container. After 90 days, plants were harvested, the shoots were clipped at soil surface and roots were washed from the soil. Shoots and roots were dried at $70^{\circ} \mathrm{C}$ in a ventilated chamber for 3 days, and their dry weight recorded.

\subsection{Statistical analysis}

Data obtained from the pot experiments were evaluated using a factorial ANOVA tests to determine the main and interactive effect of the fixed factors: target plants, leaf litter species, decomposition age and endophytic fungi status. Three-way ANOVA was done for each target species testing the effect of litter species, litter age and presence of endophytic fungi. Duncan's pairwise comparisons test was used to compare individual means. Levels of significant differences

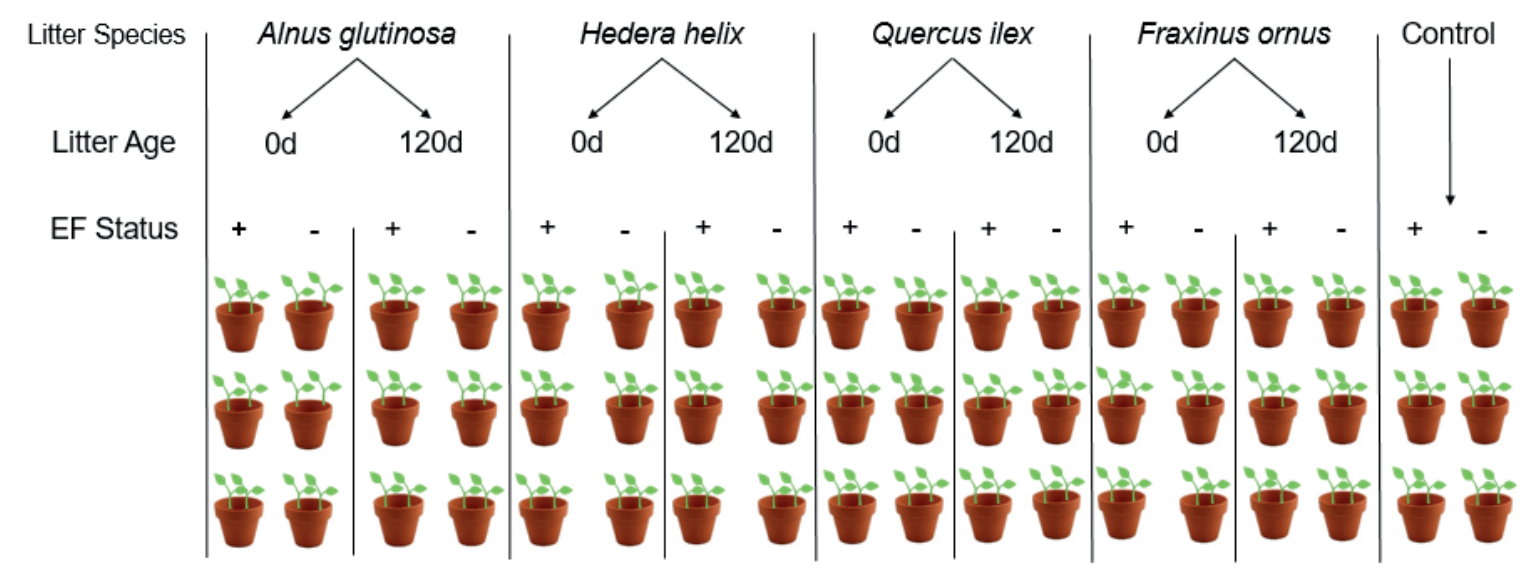

Figure 1. Schematic view of the experimental design: 3 replicates were made of each endophytic status, 4 litter species were tested (Alnus glutinosa, Hedera helix, Quercus ilex and Fraxinus ornus) at two different ages ( $0 \mathrm{~d}$ as undecomposed litter and after 120 days of decomposition); thus, 8 types of experimental units were obtained. + refers to the presence of fungal endophytes and - refers to the fungicide treated seeds and therefore their absence. The total number of the pots is 54 including the 6 of the control without litter. This experimental design applies to Trifolium repens (shown in the picture) and Triticum durum, therefore, a total of 108 pots were used. 
Table 1. Litter chemical traits of the four tested plant species at two decomposition stages assessed by elemental and proximate analyses. Different letters indicate significantly different groups (Duncan test, $\mathrm{P}<0.05$ ).

\begin{tabular}{|c|c|c|c|c|c|c|c|}
\hline Litter & Litter age & Labile C (\%) & Cellulose $(\%)$ & Lignin (\%) & $\mathrm{N}(\%)$ & $\mathrm{C} / \mathrm{N}$ & Lignin $/ \mathrm{N}$ \\
\hline \multirow{2}{*}{ A. glutinosa } & 0 days & $79.38 \mathrm{a}$ & $8.46 \mathrm{a}$ & $10.55 \mathrm{a}$ & $2.07 \mathrm{a}$ & $21.73 a$ & $5.09 \mathrm{a}$ \\
\hline & 120 days & $46.64 b$ & $26.43 b$ & $18.71 b$ & $2.02 \mathrm{a}$ & $22.27 \mathrm{a}$ & $9.28 \mathrm{a}$ \\
\hline \multirow{2}{*}{ H. helix } & 0 days & $70.46 a$ & $23.36 \mathrm{a}$ & $5.77 \mathrm{a}$ & $2.00 \mathrm{a}$ & $22.5 \mathrm{a}$ & $2.89 \mathrm{a}$ \\
\hline & 120 days & $60.52 a$ & $10.91 b$ & $26.49 b$ & $1.82 \mathrm{a}$ & $24.72 \mathrm{a}$ & $14.55 \mathrm{~b}$ \\
\hline \multirow{2}{*}{ F. ornus } & 0 days & $74.08 \mathrm{a}$ & $15.54 \mathrm{a}$ & $10.02 \mathrm{a}$ & $1.65 \mathrm{a}$ & $27.27 \mathrm{a}$ & $6.09 a$ \\
\hline & 120 days & $62.12 \mathrm{a}$ & $15.35 \mathrm{a}$ & $20.13 b$ & $2.05 \mathrm{a}$ & $21.95 b$ & $9.82 \mathrm{a}$ \\
\hline \multirow{2}{*}{ Q. ilex } & 0 days & $58.74 \mathrm{a}$ & $22.74 a$ & $18.39 a$ & $1.39 \mathrm{a}$ & $32.37 \mathrm{a}$ & $13.23 \mathrm{a}$ \\
\hline & 120 days & $41.13 \mathrm{a}$ & $7.79 b$ & $50.13 b$ & $2.22 \mathrm{a}$ & $20.27 b$ & $22.58 b$ \\
\hline
\end{tabular}

Table 2. Summary of the Factorial ANOVA testing for main and interactive effects of EF on Triticum durum total biomass in the presence of different litter species at different ages of decomposition. *: The mean difference is significant at the 0.05 level.

\begin{tabular}{|c|c|c|c|c|c|}
\hline Categorical predictor & $\begin{array}{l}\text { Sum of } \\
\text { squares }\end{array}$ & $\begin{array}{l}\text { Degree of } \\
\text { freedom }\end{array}$ & $\begin{array}{c}\text { Mean } \\
\text { squares }\end{array}$ & F-value & P-value \\
\hline Litter species & 2.28 & 3 & 0.76 & 7.9 & $0.000^{*}$ \\
\hline Decomposition age & 31.10 & 1 & 31.10 & 323.1 & $0.000^{*}$ \\
\hline EF status & 1.30 & 1 & 1.30 & 13.5 & $0,001^{*}$ \\
\hline Litter species * Decomposition age & 0.28 & 3 & 0.09 & 1.0 & 0.415 \\
\hline Litter species * EF status & 0.19 & 3 & 0.06 & 0.7 & 0.580 \\
\hline Decomposition age * EF status & 0,62 & 1 & 0.62 & 6.4 & $0.017^{*}$ \\
\hline Litter species * Decomposition age * EF status & 0.09 & 3 & 0.03 & 0.3 & 0.813 \\
\hline
\end{tabular}

were assessed at $\mathrm{P}<0,05$. All analyses were performed with STATISTICA 13.3 software.

\section{Results}

\subsection{Litter chemical traits}

Leaf litter chemical traits displayed a broad variability with $\mathrm{C} / \mathrm{N}$ and lignin $/ \mathrm{N}$ ratios being higher for $Q$. ilex and lower for H. helix and A. glutinosa (Table 1). Expectedly, C/N ratio decreased with litter age for $F$. ornus and $Q$. ilex while for A. glutinosa and H. helix it remained almost unchanged. However, lignin/ $\mathrm{N}$ ratio consistently increased along the decomposition in all litter species with a significant increase for the $H$. helix and $Q$. ilex. Lignin concentration changed during decomposition and with litter species, generally increasing with litter age. Litter $\mathrm{N}$ content, on the other hand, has barely varied during decomposition with a slight decrease in the case of $A$. glutinosa and H. helix, and a slight increase for F. ornus and $Q$. ilex. Differently, cellulose content increased with litter age for A. glutinosa while it has highly decreased in the case of $H$. helix and $Q$. ilex. For $F$. ornus, cellulose content showed no changes with litter age.

\subsection{Plant response to litter amendment and presence of endophytic fungi}

The total biomass of both $T$. durum and T. repens was affected significantly by leaf litter species, decomposition age, and seed-associated endophytic fungi (Tables 2 and 3 ). Without endophytic fungi, litter from different species showed variable effects before and after decomposition processes. In general, a significant inhibitory effect on total biomass was evident for undecomposed leaf material of forbs (H. helix) and woody species (Q. ilex and F. ornus) (Fig. 2). However, the undecomposed litter of the nitrogen fixing $A$. glutinosa showed no inhibitory effects on T. repens (Fig. 2). Nevertheless, the decomposed litter has shown less inhibition, no inhibition or in some cases, a growth promoting effect. For example, the litter of $A$. glutinosa, H. helix and $Q$. ilex showed a growth promoting effect on $T$. repens after the decomposition process. Statistical analyses showed that the interactive effect of leaf litter species and decomposition age affected significantly total biomass of $T$. repens but not of $T$. durum (Tables 2 and 3). Thus, for T. durum, the fresh litter encloses more inhibitory effect than the decomposed one for all tested litter species. While for T. repens, the same pattern 
Table 3. Summary of the Factorial ANOVA testing for main and interactive effects of EF on Trifolium repens total biomass in the presence of different litter species at different ages of decomposition. *: The mean difference is significant at the 0.05 level.

\begin{tabular}{|c|c|c|c|c|c|}
\hline Categorical predictor & $\begin{array}{l}\text { Sum of } \\
\text { squares }\end{array}$ & $\begin{array}{l}\text { Degree of } \\
\text { freedom }\end{array}$ & $\begin{array}{c}\text { Mean } \\
\text { squares }\end{array}$ & F-value & P-value \\
\hline Litter species & 114.9 & 3 & 38.31 & 252.3 & $0.000^{*}$ \\
\hline Decomposition age & 39.6 & 1 & 39.62 & 260.9 & $0.000^{*}$ \\
\hline EF status & 5.0 & 1 & 4.96 & 32.7 & $0,000^{*}$ \\
\hline Litter species * Decomposition age & 10.8 & 3 & 3.60 & 23.7 & $0.000^{*}$ \\
\hline Litter species $*$ EF status & 2.3 & 3 & 0.78 & 5.1 & $0.005^{*}$ \\
\hline Decomposition age * EF status & 1.3 & 1 & 1.28 & 8.4 & $0.007^{*}$ \\
\hline Litter species $*$ Decomposition age * EF status & 6.1 & 3 & 2.03 & 13.4 & $0.000^{*}$ \\
\hline
\end{tabular}
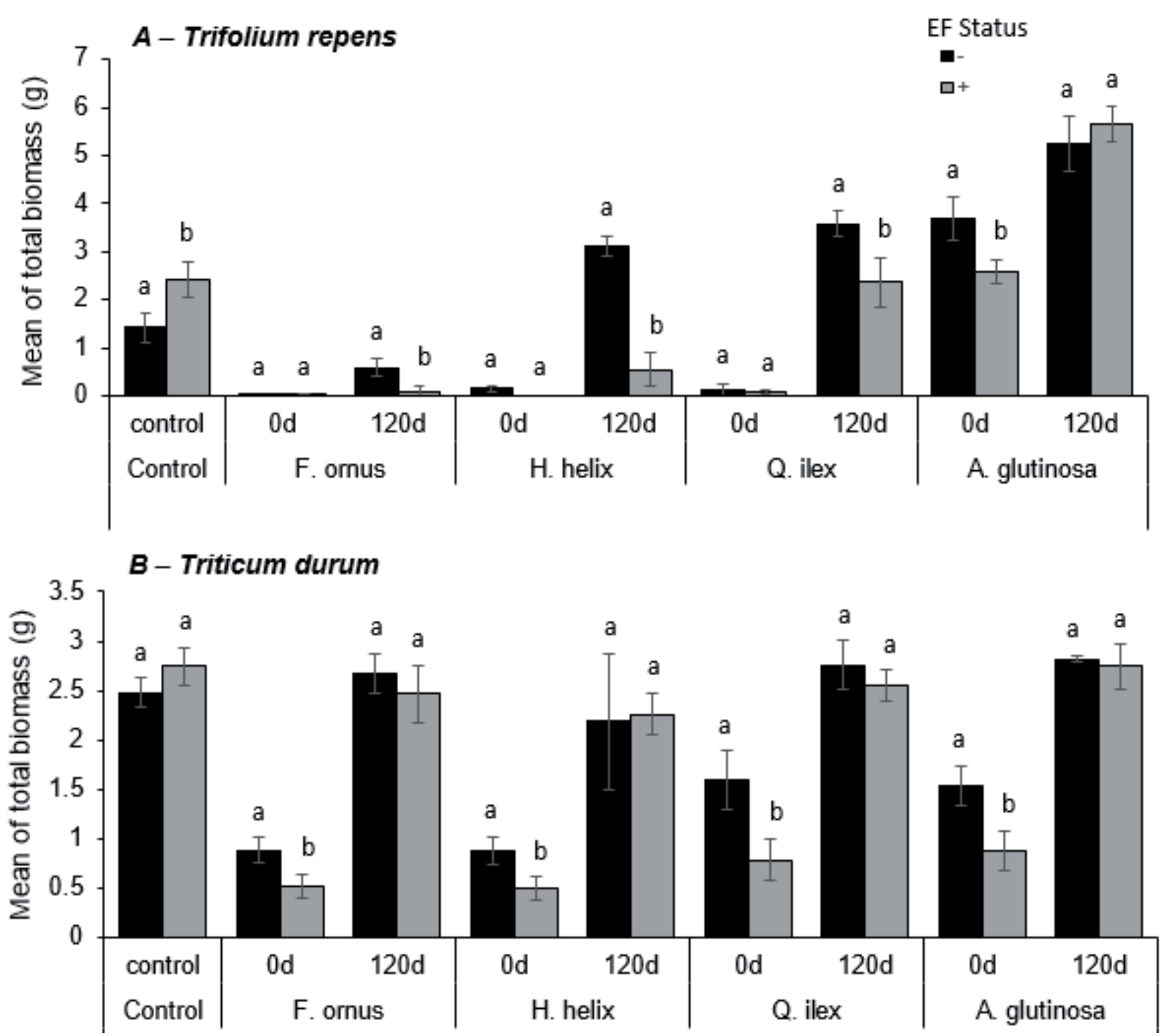

Figure 2. Mean of total biomass (g.plant ${ }^{-1}$ ) of Trifolium repens (A) and Triticum durum (B) in the presence of four litter species: $A$. glutinosa, F. ornus, H. helix and Q. ilex, at two ages: before ( $0 \mathrm{~d})$ and after 120 days of laboratory decomposition (120 d), in the presence or absence of seed-associated endophytic fungi (- and + , respectively). Data are represented as means SD $(n=3)$. Different letters indicate significant differences among treatments for each plot (Duncan test, $\mathrm{P}<0.05$ ). 
is not confirmed, because both fresh and decomposed litter can exhibit a high inhibition effect on plant total biomass.

Endophyte free plants showed an improvement of the seedlings capacity to tolerate fresh undecomposed litter inhibitory effect when compared to untreated plants (Fig. 2). This applies to all undecomposed tested litter species; the total biomass was higher without endophytic fungi and the seedlings showed more sensitivity to litter with their presence. However, in the control, seed associated endophytic fungi exhibited a beneficial effect by increasing the total biomass (Fig. 2). After 120 days of decomposition, the inhibitory effect of litter decreased in all litter species tested, although the effect was not completely disappeared as in the case of $T$. repens in presence of $F$. ornus and $H$. helix litter. It has been observed, in this case, that as long as the litter stress remains, the presence of endophytic fungi enhances the disadvantageous effect of litter, while in the absence of litter inhibitory effect the presence of fungi increase the total biomass (Fig. 2). However, for H. helix and Q. ilex decomposed litter, the absence of fungal endophytes promoted the total biomass of $T$. repens. Meanwhile in T. durum, results showed that decomposed litter demonstrated no effect on the plant total biomass, both in the absence and the presence of seed-associated endophytic fungi.

\section{Discussion}

Our results confirmed that undecomposed litter had broad inhibitory effects on plant growth (Bonanomi et al. 2017). The phytotoxicity of leaf litter seems to be a general phenomenon, not limited to some allelopathic species, since all the fresh undecomposed litter species tested produce significant inhibitory effects on the total biomass, with exception of A. glutinosa fresh litter on T. repens. Moreover, the present study indicates that the inhibitory effect of litter is significantly influenced by both litter species and age of decomposition (Chou et al. 1976, Bonanomi et al. 2006, Zhang et al. 2015).

In contrast to allelochemicals directly extracted from living organs or plant tissues, the activity of organic compounds released from decomposing leaf litter is highly affected by the soil, thus their concentration, composition, structure, and effect might be remarkably different (Yenish et al. 1995, Blum et al. 1998, Walker et al. 2003). The necessary conditions for the appearance of inhibitory effects occur when allelochemicals reach the receiver plant in their active structure and at an effective concentration, thereby undecomposed and decomposed litter often displays different level of inhibition (Zhang et al. 2015). In this study, undecomposed leaf litter of all species exhibited a strong inhibition of the growth. The intensity of phytotoxicity was high in the case of $H$. helix and $F$. ornus, followed by $Q$. ilex while $A$. glutinosa proved to be the least toxic. Bonanomi et al (2011) have demonstrated the existence of a weak but positive correlation between $\mathrm{N}$ release and root growth inhibition, excluding that the inhibition exhibited by H. helix and F. ornus is due to N immobilization, given the large $\mathrm{N}$ release by these litter materials during decay. However, after $120 \mathrm{~d}$ of decomposition, the phytotoxicity is known to decrease significantly, with a cor- responding increase of the seedlings total biomass. Indeed, in the case of A. glutinosa, the decomposed leaf litter has even demonstrated a biomass increasing effect instead of phytotoxicity for T. repens. Correspondingly, Zhang et al (2015) have demonstrated that an extract of decomposed leaf litter of Eucommia ulmoides Oliv. has accelerated the growth of roots, whilst an extract of undecomposed litter had resulted in significant inhibition. Accordingly, Inderjit (2005) stated that soil microbes were able to break down litter allelochemicals into inactive substances. Moreover, litter after decomposition is considered to be a source of different nutrients. It has been proven that these nutrients lessen the allelopathy and the associated production of stable organic matter helps in the absorption of allelochemical compounds such as caffeic acids, ferulic acid and salicylic acid, which soften their phytotoxicity (Loffredo et al. 2005). Therefore, all of these interactions can antagonize the negative effects of allelochemicals (Zhang et al. 2015). On the other hand, the inhibition caused by allelochemicals may be increased by soil biochemical conditions. For instance, Pollock et al (2009) reported that when catechins are combined with metal ions, their allelopathic inhibitory effect is strongly accelerated. These results indicate that under the biochemical and microbial conditions of soil, allelochemical compounds that inhibit the growth can diffuse, decompose or accumulate in the soil, and their structure or activities may be altered.

Interestingly and unexpectedly, our study revealed that in the presence of litter stress, seed-associated endophytic fungi have strengthened the inhibitory effect since the total biomass was significantly reduced in their presence. On the contrary, in the control as well after the disappearance of the inhibitory effect because of decomposition, endophytic fungi increased total biomass. This could mean that seed-associated fungal endophytes exhibit their negative effect in the presence of litter allelopathy regardless of the host plant. Omacini et al (2004) found, by measuring litter decomposition rate, that litter decomposition of Lolium multiflorum was $17 \%$ slower with the Neotyphodium endophyte using microcosms placed outdoors and by nearly $8 \%$ under field conditions. However, in the case of $T$. repens, the absence of fungal endophytes in presence of $Q$. ilex decomposed litter has improved the total biomass. This could result from the presence of litter itself rather than its phytotoxicity given that this litter species displayed large difference compared to others in terms of cellulose and lignin contents.

The findings of this study have to be seen in light of a limitation regarding the molecular identification of the naturally seed-associated fungal endophytes of the two focal plants. However, the main goal of the study is to evaluate primarily the general effect of endophytic fungi on the plant response to litter stress. Previous studies have reported that $T$. repens is commonly colonized mostly by dark septate endophytes ( $\mathrm{Li}$ et al. 2005, Sieber and Grünig 2013), while T. durum is mostly colonized by fungal endophytes belonging to the Ascomycetes phylum (Sadrati et al. 2013). Moreover, we lack an integrated understanding of the mechanisms by which endophytic fungi respond differently in the presence and the absence of different litter species. Previous works have suggested various 
explanations. First, it could be that these fungi affect the plant associated microbiota in the soil directly by secreting toxic alkaloids as a response to allelopathic stress. For example, some studies have reported negative interactions between fungal endophytes and secondary decomposer fungal saprotrophs (Dowson et al. 1988, Fukasawa et al. 2009). Moreover, the reason could be the control of root exudate by endophytic fungi, these latter may alter some metabolic pathways of their host plant, resulting in several changes in litter components and in an increase in toxic substances (Schmidt et al. 1982, Lyons et al. 1990, Purahong and Hyde 2011). Furthermore, endophytic fungi live inside the plant tissues in a continuum lifestyle, ranging from mutualistic to pathogenic depending on the outside conditions (Saikkonen et al. 1998). Therefore, these results may be explained by the modulation of the activity of associated endophytic fungi that shift from mutualistic to opportunistic pathogenic under the allelopathy stress, which has reinforced the inhibitory effect of allelochemicals. It will be very interesting to look at interactions between the endophytic microbiome and the occurrence of the inhibitory effect due to self-DNA (Mazzoleni et al. 2015). Also in the case of autotoxicity, the dynamics of decomposition could have different outcomes mediated by plant-microbes interactions so far neglected.

The negative effect of seed-associated endophytic fungi on the total biomass in the presence of litter demonstrates that these microbes have an indirect effect on the plant-litter interaction. Our data suggest that seed-associated endophytic fungi may have an important role in the plant community dynamics by affecting plant-plant interaction and possibly modulating species coexistence. Along this line, a recent study demonstrated that Centaurea stoebe L. cannot only expand, but can perform better in new ranges indirectly by escaping their associated endophytes (Geisen et al. 2017).

\section{Conclusion}

In this study, we found that, aside from the important role of leaf litter decomposition in biogeochemical cycles, litter also has a strong effect on plant-plant interaction that depend on presence of endophytic fungi. In detail, seed-associated endophytic fungi demonstrated to enhance the inhibitory effect of litter and could affect plant coexistence. Further studies are required to understand the exact mechanism by which fungal endophyte exhibit their role in affecting plant-litter interaction and in structuring plant communities. Special attention should be given as well to the effect of these microbes on the plant growth and tolerance in the presence of conspecific litter.

Acknowledgments: The research reported here was funded by the Erasmus Mundus program of the European Union. We would like to show our gratitude to professor V. Lanzotti, the delegate of Erasmus and international relationships at the Department of Agriculture (Federico II University of Naples, Italy) for significant support and assistance during the Erasmus period.

\section{References}

Aerts, R. 1997. Climate, leaf litter chemistry and leaf litter decomposition in terrestrial ecosystems: a triangular relationship. Oikos 79:439-449.

An, M., Pratley, J.E. and Haig, T. 2001. Phytotoxicity of Vulpia residues. IV. Dynamics of allelochemicals during decomposition of Vulpia residues and their corresponding phytotoxicity. J. Chem. Ecol. 27:395-407.

Bamisile, B.S., Dash, C.K., Akutse, K.S., Keppanan, R. and Wang, L. 2018. Fungal endophytes: beyond herbivore management. Front. Microbiol. 9:544.

Berg, B. and Laskowski, R. 2005. Litter decomposition: a guide to carbon and nutrient turnover. Adv. Ecol. Res. 38:3-4.

Berg, B. and McClaugherty, C. 2014. Plant Litter: Decomposition, Humus Formation and Carbon Sequestration. Third Edition. Springer-Verlag, Berlin.

Blum, U., Shafer, S.R. and Lehman, M.E. 1999. Evidence of inhibitory allelopathic interactions involving phenolic acids in field soil: concepts vs an experimental model. Crit. Rev. Plant Sci. 18:673-693.

Blum, U. 1998. Effects of microbial utilization of phenolic acids and their phenolic acid breakdown products on allelopathic interactions. J. Chem. Ecol. 24:685-708.

Bonanomi, G., Incerti, G., Barile, E., Capodilupo, M., Antignani, V., Mingo, A., Lanzotti, V., Scala, F. and Mazzoleni, S. 2011. Phytotoxicity, not nitrogen immobilization, explains plant litter inhibitory effects: evidence from solid-state 13C NMR spectroscopy. New Phytol. 191:1018-1030.

Bonanomi, G., Incerti, G., Giannino, F., Mingo, A., Lanzotti, V. and Mazzoleni, S. 2013. Litter quality assessed by solid state ${ }^{13} \mathrm{C}$ NMR spectroscopy predicts decay rate better than $\mathrm{C} / \mathrm{N}$ and Lignin/N ratios. Soil Biol. Biochem. 56:40-48.

Bonanomi, G., Cesarano, G., Lombardi, N., Motti R., Scala, F., Mazzoleni, S. and Incerti, G. 2017. Litter chemistry explains contrasting feeding preferences of bacteria, fungi, and higher plants. Sci. Rep. 7:9208.

Bonanomi, G., Rietkerk, M., Dekker, S. et al. 2005. Negative plantsoil feedback and positive species interaction in a herbaceous plant community. Plant Ecol. 181:269-278.

Bonanomi, G., Sicurezza, M.G., Caporaso, S., Esposito, A. and Mazzoleni, S. 2006. Phytotoxicity dynamics of decaying plant materials. New Phytol. 169:571-578.

Campanile, G., Ruscelli, A. and Luisi, N. 2007. Antagonistic activity of endophytic fungi towards Diplodia corticola assessed by in vitro and in planta tests. Eur. J. Plant Pathol. 117:237-246.

Cao, R., Liu, X.G., Gao, K.X., Kang, M.K., Z.S., GJF, Dai, Y. and Wang, X. 2009. Mycoparasitism of endophytic fungi isolated from reed on soilborne phytopathogenic fungi and production of cell wall-degrading enzymes in vitro. Curr. Microbiol. 59:584592.

Cesarano, G., Zotti, M., Antignani, V., Marra, R., Scala, F. and Bonanomi, G. 2017. Soil sickness and negative plant-soil feedback: a reappraisal of hypothesis. Int. J. Plant Pathol. 99:545570.

Cherry, J.R., Lamsa, M.H., Schneider, P., Vind, J., Svendsen, A., Jones,A. and Pedersen, A.H. 1999. Directed evolution of a fungal peroxidase. Nat. Biotechnol. 17:379-384.

Chou, C.H. and Patrick, Z.A. 1976. Identification and phytotoxic activity of compounds produced during decomposition of corn and rye residues in soil. J. Chem. Ecol. 2:369-387. 
Cleveland, C.C. and Liptzin, D. 2007. C:N:P stoichiometry in soil: is there a "Redfield Ratio" for the microbial biomass? Biogeochemistry 85:235-252.

Cochrane, V.W. 1948. The role of plant residues in the etiology of root rot. Phytopathology 38:185-196.

Dowson, C.G., Rayner, A.D.M. and Boddy, L. 1988. Inoculation of mycelial cord-forming basidiomycetes into woodland soil and litter I. Initial establishment. New Phytol. 109:335-341.

Elmi, A.A. and West, C.P. 1995. Endophyte infection effects on stomatal conductance, osmotic adjustment and drought recovery of tall fescue. New Phytol. 131:61-67.

Fukasawa, Y., Osono, T. and Takeda, H. 2009. Effects of attack of saprobic fungi on twig litter decomposition by endophytic fungi. Ecol. Res. 24:1067-1073.

Geisen, S., Kostenko, O., Cnossen, M.C., ten Hooven, F.C., Vreš, B. and van der Putten, W.H. 2017. Seed and root endophytic fungi in a range expanding and a related plant species. Frontiers Microbiol. 8:1645.

Gessner, M.O. 2005. Proximate lignin and cellulose. In: Graca, M.A.S., Bärlocher, F. and Gessner, M.O. (eds.), Methods to Study Litter Decomposition. A Practical Guide. Springer Verlag, The Netherlands. pp. 115-120.

Giordano, L., Gonthier, P., Varese, G.C., Miserere, L. and Nicolotti, G. 2009. Mycobiota inhabiting sapwood of healthy and declining Scots pine (Pinus sylvestris L.) trees in the Alps. Fungal Divers. 38:69-83.

Hardoim, P.R., Van Overbeek, L.S., Berg, G., Pirttilä, A.M., Compant, S., Campisano, A. et al. 2015. The hidden world within plants: ecological and evolutionary considerations for defining functioning of microbial endophytes. Microbiol. Mol. Biol. Rev. 79: $293-320$

Hata, K., Tsuda, M. and Futai, K. 1998. Seasonal and needle agedependent changes of the endophytic mycobiota in Pinus thunbergii and Pinus densiflora needles. Can. J. Bot. 76:245-250.

Hyde, K.D. and Soytong, K. 2008. The fungal endophyte dilemma. Fungal Divers. 33:163-173.

Inderjit, I. 2005. Soil microorganisms: an important determinant of allelopathic activity. Plant Soil. 274:227-236.

Jäderlund, A., Zackrisson, O. and Nilsson, M.C. 1996. Effect of bilberry (Vaccinium myrtillus L.) litter on seed germination and early seedling growth of four boreal tree species. J. Chem. Ecol. 22:973-986.

Kia, S.H., Glynou, K., Nau, T., Thines, M., Piepenbring, M. and Macia-Vicente, J.G. 2017. Influence of phylogenetic conservatism and trait convergence on the interactions between fungal root endophytes and plants. ISME J. 11:777-790.

Kjoller, A. and Struwe, S. 1992. Functional groups of micro-fungi in decomposition. In: Carroll, G.C. and Wicklow, D.T. (eds.), The Fungal Community: Its Organization and Role in the Ecosystem. Marcel Dekker, New York. 2:619-630.

Krishna, M.P. and Mohan, M. 2017. Litter decomposition in forest ecosystems: a review. Energ. Ecol. Environ. 4:236-249.

Li, L.F., Yang, A. and Zhao, Z.W. 2005. Seasonality of arbuscular mycorrhizal symbiosis and dark septate endophytes in a grassland site in southwest China. FEMS Microbiol Ecol. 54:367-373.

Loffredo, E., Monaci, L. and Senesi, N. 2005. Humic substances can modulate the allelopathic potential of caffeic, ferulic, and salicylic acids for seedlings of lettuce (Lactuca sativa L.) and tomato (Lycopersicon esculentum Mill.). J. Agric. Food Chem. 53:9424-9430.

Lyons, P.C., Evans, J.J. and Bacon, C.W. 1990. Effects of the fungal endophyte Acremonium coenophialum on nitrogen accumula- tion and metabolism in tall fescue. Plant Physiol. (Rockville). $92: 726-732$

Makino, T., Takahashi, T., Sakurai, Y. and Nanzyo, M. 1996. Influence of soil chemical properties on adsorption and oxidation of phenolic acids in soil suspension. Soil Sci. Plant Nutr. 42:867-879.

Malinowski, D.P., Alloush, G.A. and Belesky, D.P. 2000. Leaf endophyte Neotyphodium coenophialum modifies mineral uptake in tall fescue. Plant Soil 227:115-126.

Manzoni, S., Trofymow, J.A., Jackson, R.B. and Porporato, A. 2010. Stoichiometric controls on carbon, nitrogen, and phosphorus dynamics in decomposing litter. Ecol. Monogr. 80:89-106.

Mayerhofer, M.S., Kernaghan, G. and Harper, K.A. 2012. The effects of fungal root endophytes on plant growth: a meta-analysis. Mycorrhiza 23:119-128.

Mazzoleni, S., Bonanomi, G., Incerti, G., Chiusano, M.L., Termolino, P., Mingo, A., Senatore, M., Giannino, F., Cartenì, F., Rietkerk, M. and Lanzotti, V. 2015. Inhibitory and toxic effects of extracellular self-DNA in litter: a mechanism for negative plant-soil feedbacks? New Phytol. 205:1195-1210.

McGroddy, M.E., Daufresne, T. and Hedin, L.O. 2004. Scaling of $\mathrm{C}: \mathrm{N}: \mathrm{P}$ stoichiometry in forests worldwide: implications of terrestrial Redfield-type ratios. Ecology 85:2390-2401.

Meentemeyer, V. 1978. Macroclimate and lignin control of litter decomposition rates. Ecology 59:465-472.

Newsham, K.K. 2011. A meta-analysis of plant responses to dark septate root endophytes. New Phytol. 190:783-793.

Omacini, M., Chaneton, E.J., Ghersa, C.M. and Otero, P. 2004. Do foliar endophytes affect grass litter decomposition? A microcosm approach using Lolium multiflorum. Oikos 104:581-590.

Peay, K.G., Kennedy, P.G. and Talbot, J.M. 2016. Dimensions of biodiversity in the Earth mycobiome. Nat. Rev. Microbiol. 14:434447.

Pollock, J.L., Callaway, R.M., Thelen, G.C. and Holben, W.E. 2009. Catechin-metal interactions as a mechanism for conditional allelopathy by the invasive plant Centaurea maculosa. J. Ecol. 97: 1234-1242.

Purahong, W. and Hyde, K.D. 2011. Effects of fungal endophytes on grass and non-grass litter decomposition rates. Fungal Divers. 47:1-7.

Puri, A., Padda, K.P. and Chanway, C.P. 2016. Evidence of nitrogen fixation and growth promotion in canola (Brassica napus L.) by an endophytic diazotroph Paenibacillus polymyxa P2b-2R. Biol. Fertil. Soils 52:119-125.

Redman, R.S., Sheehan, K.B., Stout, R.G., Rodriguez, R.J. and Henson, J.M. 2002. Thermotolerance generated by plant/fungal symbiosis. Science 298:1581.

Sadrati, N., Duoud, H., Zerroug, A., Duhamna, S. and Bouharati, S. 2013. Screening of antimicrobial and antioxidant secondary metabolites from endophytic fungi isolated from wheat (Triticum durum). J. Plant Prot. Res. 53:128-136.

Saikkonen, K., Faeth, S.H., Helander, M. and Sullivan, T.J. 1998. Fungal endophytes: A continuum of interactions with host plants. Annu. Rev. Ecol. Evol. Syst. 29:319-343.

Schenk, H.J., Callaway, R.M. and Mahall, B.E. 1999. Spatial root segregation: are plants territorial? Adv. Ecol. Res. 28:146-180.

Schmidt, S.P., Carl, S.H., Edward, M.C., Norman, D.D., Smith, L.A., Harold, W.G. and Jimmy, L.H. 1982. Association of an endophytic fungus with fescue toxicity in steers fed Kentucky-31 tall fescue seed or hay. J. Anim. Sci. 55:1259-1263.

Schulz, B., Rommert, A.K., Dammann, U., Aust, H.J. and Strack, D. 1999. The endophyte-host interaction: a balanced antagonism? Mycol. Res. 10:1275-1283. 
Shaukat, S.S., Siddiqui, I.A., Khan, G.H. and Zaki, M.J. 2002. Nematicidal and allelopathic potential of Argemone mexicana, a tropical weed. Plant Soil 245:239-247.

Sikora, R.A., Pocasangre, L., Felde, A.Z., Niere, B., Vu, T.T. and Dababat, A.A. 2008. Mutualistic endophytic fungi and in-planta suppressiveness to plant parasitic nematodes. Biol. Control. 46:15-23.

Sikora, R.A., Schäfer, K. and Dababat, A.A. 2007. Modes of action associated with microbially induced in planta suppression of plant-parasitic nematodes. Australas. Plant Path. 36:124-134.

Sieber, T.N. and Grünig, C.R. 2013. Fungal root endophytes. In: A Eshel and T. Beeckman (eds.), Plant Roots - The Hidden Half. CRC Press, Boca Raton, FL. USA. Taylor \& Francis Group. Chap. 38. pp. 1-49.

Song, Z., Kennedy, P.G., Liew, F.J. and Schilling, J.S. 2017. Fungal endophytes as priority colonizers initiating wood decomposition. Funct. Ecol. 31:407-418.

Souto, C., Pellissier, F. and Chiapusio, G. 2000. Allelopathic effects of humus phenolics on growth and respiration of mycorrhizal fungi. ¡J. Chem. Ecol. 26:2015-2023.

Suryanarayanan, T.S. 2013. Endophyte research: going beyond isolation and metabolite documentation. Fungal Ecol. 6:561-568.

Van der Putten, W.H., Peters, B.A.M. and van den Berg, M.S. 1997. Effect of litter on substrate conditions and growth of emergent macrophytes. New Phytol. 135:527-537.

Vega, F.E., Posada, F., Aime, M.C., Ripoll, M.P., Infante, F. and Rehner, S.A. 2008. Entomopathogenic fungal endophytes. Biol. Control. 46:72-82.
Vesterdal, L. 1999. Influence of soil type on mass loss and nutrient release from decomposing foliage litter of beech and Norway spruce. Can. J. For. Res. 29:95-105.

Vu, T., Hauschild, R. and Sikora, R.A. 2006. Fusarium oxysporum endophytes induced systemic resistance against Radopholus similis on banana. Nematology 8:847-852.

Walker, T.S., Bais, H.P., Grotewold, E. and Vivanco, J.M. 2003. Root exudation and rhizosphere biology. Plant Physiol. 132:44-51.

Yenish, J.P., Worsham, A.D. and Chilton, W.S. 1995. Disappearance of DIBOA-glucoside, DIBOA, and BOA from rye (Secale cereale L.) cover crop residue. Weed Sci. 43:18-20.

Yue, Q., Bacon, C.W. and Richardson, M.D. 1998. Biotransformation of 2-benzoxazolinone and 6-methoxy-benzoxazolinone by Fusarium moniliforme. Phytochemistry 48:451-454.

Zhang, X., Zengwen, L.I.U., Nan, T.I.A.N., Nhu Trung, L.U.C., Bochao, Z.H.U. and Yuanhao, B.I.N.G. 2015. Allelopathic effects of decomposed leaf litter from intercropped trees on rape. Turk. J. Agric For. 39:898-908.

Zikmundová, M., Drandarov, K., Bigler, L., Hesse, M. and Werner, C. 2002. Biotransformation of 2-benzoxazolinone and 2-hydroxy-1,4-benzoxazin-3-one by endophytic fungi isolated from Aphelandra tetragona. Appl. Environ. Microbiol. 68:4863-4870.

Received May 13, 2019 Revised August 14, 2019 Accepted August 24, 2019 